Michat Sajewicz

Lublin

\title{
Transformacja imion chrześcijańskich mieszkańców XVI-wiecznego miasta Kleszczele na Podlasiu
}

Słowa kluczowe: Podlasie, Kleszczele, XVI w., imiona chrześcijańskie, transformacja

\section{Część wstępna}

Kleszczele powstały na granicy ziemi bielskiej z brzeską, w miejscu przeprawy przez rzekę Nur (obecnie Nurzec) na trakcie prowadzącym z Grodna do Brześcia. Autor monografii o Kleszczelach M. Roszczenko zauważa: „Okolice te były dogodnym miejscem na założenie miasta. Właśnie tutaj droga do Brześcia rozgałęziała się na Drohiczyn i dalej na Warszawę. Przebiegała tędy także droga z Brześcia do Bielska. To skrzyżowanie kilku dróg dodatkowo przemawiało za utworzeniem w tym miejscu lokalnego ośrodka miejskiego. Rzeka Nur (Nurzec) przepływająca przez Kleszczele nie była co prawda żeglowną, ale umożliwiała budowanie młynów, niezbędnych przecież w każdym ówczesnym mieście" [Roszczenko 2002, 24]. J. Zieleniewski uważa, że już w XIV-XV w. najprawdopodobniej istniał tu wielkoksiążęcy dwór myśliwski [Zieleniewski 1991, 201]. Odmiennego zdania jest M. Roszczenko, który reprezentuje pogląd, ,że nie był to dwór myśliwski, ponieważ w dokumencie lokacyjnym Kleszczel wspomina się o paszni dwornoj. Wynikałoby z tego, że było tam jakieś gospodarstwo rolne, coś na wzór późniejszego folwarku z odpowiednimi zabudowaniami. W średniowieczu na bardziej uczęszczanych traktach, a z tych z reguły korzystali królowie i książęta, co kilkadziesiąt kilometrów musiały znajdować się jakieś zabudowania - dwory wielkoksiążęce, w których ich orszaki mogły znaleźć pożywienie i schronienie na nocleg" [Roszczenko 2001, 24]. Podobny pogląd 
wyraża również znany badacz historii Podlasia A. Jabłonowski [Jabłonowski 1909b, 30].

Historyczna nazwa Kleszczele pojawiła się w dokumentach już w XV wieku [Miasto i gmina Kleszczele]. Znamienną datę w historii Kleszczeli stanowi jednak rok 1513. W tym właśnie roku po śmierci królowej Heleny, wdowy po królu i wielkim księciu litewskim Aleksandrze, dobra wielkoksiążęce na Podlasiu, wraz z Bielskiem, Surażem, Brańskiem, Narwią i Kleszczelami, zostały zastawione Radziwiłłom [Jabłonowski 1909a, 107]. „Właśnie wojewoda wileński i kanclerz wielki litewski Mikołaj Mikołajewicz Radziwiłł na polecenie króla Zygmunta Starego dokonał pierwszej nieudanej lokacji miasta. [...] Niestety nie wiemy, w którym roku ta pierwsza, nieudana próba założenia miasta miała miejsce" [Roszczenko 2002, 25]. I. Sankiewicz podaje rok 1506 [Sankiewicz 1845, 172-179], natomiast M. Roszczenko za bardziej prawdopodobny uznaje termin późniejszy i sytuuje go „pomiędzy 1513, kiedy podlaskie królewszczyzny przechodzą we władanie Radziwiłłów, a 1522 r. - rokiem śmierci kanclerza [Roszczenko 2002, s. 25].

W 1523 r. większość królewszczyzn na Podlasiu, w tym również Kleszczele, wykupił od Radziwiłłów Olbracht Gasztołd, ówczesny wojewoda wileński i starosta bielski. Jemu to właśnie król Zygmunt Stary, jako formalny właściciel tych ziem, ponownie polecił lokować miasto Kleszczele. Król zatwierdził lokację Gasztołda i nadał miastu prawo chełmińskie swym przywilejem lokacyjnym z 22 marca 1523 roku [Kamera Wojenna i Domen Prus Nowowschodnich].

W 1553 roku Królowa Bona, żona Zygmunta Starego, wykupiła z rąk Olbrachta Gasztołda królewszczyzny ziemi bielskiej, w tym również Kleszczele. Królowa uważała, że królewszczyzny są zarządzane niewłaściwie i przynoszą dochody mniejsze od oczekiwanych. Dlatego też z inicjatywy królowej Bony dokonano na Podlasiu w 1560 roku pomiary włócznej, która przyczyniła się do zwiększenia przychodów z czynszu oraz ułatwiła ściąganie powinności.

Liczba mieszkańców Kleszczeli w połowie XVI wieku jest trudna do ustalenia, ponieważ brak jest na ten temat dokładnych informacji w źródłach. M. Roszczenko szacuje, że w tym czasie w Kleszczelach zamieszkiwało około 2000 osób. Autor stwierdza, że ,jest to szacunek bardzo niedokładny, ale wydaje się, iż liczba mieszkańców bynajmniej nie została zawyżona. Potwierdza go zresztą szacunek oparty na ilości domów. Otóż dwadzieścia lat później (1580) było w Kleszczelach 385 domów i jeżeli odliczymy nawet owych dwanaście pustych, to i tak możemy liczbę mieszkańców Kleszczeli szacować na około 2000, zakładając, że rodzina w owym okresie liczyła średnio co najmniej 5-6 osób" [Roszczenko 2002, 39]. M. Roszczenko zauważa, że Kleszczele były w XVI wieku drugim pod względem licz- 
by mieszkańców miastem Podlasia, ustępując jedynie Bielskowi [Roszczenko 2002, 39-40].

Ludność osiedlająca się w Kleszczelach pochodziła głównie z pobliskich wsi i miast ziemi bielskiej. Sądząc po imionach XVI-wiecznych mieszkańców tego miasta, zamieszkiwali tu głównie Rusini (80-90\%) i Polacy (10\%) [Roszczenko 2002, 40-41]. Pierwsze wzmianki o żydowskich mieszkańcach Kleszczeli pochodzac dopiero z 1580 roku. W tym czasie w Kleszczelach mieszkała jedna rodzina żydowska [E. R. 1934, 130].

M. Roszczenko, zauważa, że stosunkowo łatwo ,jest określić przynależność etniczną [XVI-wiecznych mieszkańców Kleszczeli - M. S.] na podstawie imion, jeżeli były one typowe (albo wyłączne) dla prawosławia bądź katolicyzmu, np. Prokop, Chwiedor, Onikiej, Taras czy Szczęsny, Bartosz, Wojciech. Trudniej to uczynić, jeżeli dane imię popularne było w obu wyznaniach, np. Pawet, Piotr, Michat, tym bardziej, iż lustrator często takie imiona nawet w odniesieniu do Rusinów podaje w wersji polskiej. Mamy więc przypadki, kiedy ten sam człowiek raz jest zapisywany jako Jakub, a następnie Jacz czy też Jan i Iwan, Leon i Lewon" [Roszczenko 2002, 40].

Słusznie zauważają badacze dziejów Podlasia, że pomiara włóczna, „dokonana ze względów fiskalnych, ma dziś ogromne znaczenie historyczne. Rejestry pomiarowe dają nam pierwszy, niekiedy jedyny, obraz poszczególnych miejscowości w dawnych stuleciach. Jest to właściwie pierwszy spis mieszkańców, czy raczej rodzin, ponieważ wymienieni są tylko właściciele określonych działek gruntów" [Roszczenko 2002, 34].

W rejestrach pomiarowych sporządzonych w $1560 \mathrm{r}$. w Kleszczelach przez S. Dziewiałtowskiego Skoczka uwzględniono ponad 600 właścicieli placów i gruntów w mieście i w pięciu sąsiednich wsiach, zwanych przedmieściami: Dobrowoda, Nurzec, Kosna, Babicze (Kuzawa) i Trubianka [ $W$ województwie podlaskim w ziemi bielskiey lustracja starostwa kleszczelewskiego; Roszczenko 2002, 323-360] Nazwiska w tym czasie były jeszcze dość rzadkie, najczęściej więc w rejestrach podawano imię i przezwisko właściciela gruntów.

Rejestry pomiarowe z 1560 r. są doskonałym i najwcześniejszym źródłem wiedzy o antroponimii szesnastowiecznych mieszkańców miasta Kleszczele i okolicznych wsi-przedmieść, w szczególności o ich imionach i przezwiskach, a także o początkach kształtowania się miejscowego systemu nazwiskowego [por. Sajewicz 2014].

Celem artykułu jest próba opisu transformacji imion chrześcijańskich XVI-wiecznych mieszkańców miasta Kleszczele i jego przedmieść, występujących w dokumencie lustracyjnym sporządzonym przez S. Dziewiałtowskiego Skoczka w 1560 roku. Były to w zdecydowanej większości ludowe 
odpowiedniki kanonicznych imion prawosławnych i katolickich. Formy te ukształtowały się $\mathrm{w}$ rezultacie transformacji dopasowującej imiona kanoniczne do struktury fonetycznej przyjmującego systemu językowego [por. Roszczenko 1979, zob. także Atlas gwar wschodniostowiańskich Białostocczyzny, t. I, 1980]. „Różnice fonetyczne zarejestrowane w odnotowanych formach imion mogą być rezultatem adaptacji imion chrześcijańskich, interferencji, określonych procesów zachodzących w rozwoju języka, jak i fluktuacji dźwiękowej o cechach przypadkowości" [Tichoniuk 2000, 15].

Wspomniany proces wpłynął na znaczne zróżnicowanie form imion mieszkańców XVI-wiecznego Podlasia, w tym również miasta Kleszczele. Niejednokrotnie w jednej miejscowości notowano kilka, a nawet kilkanaście odpowiedników imienia kanonicznego. B. Tichoniuk zauważa, że „niejednolitość fonetyczna, której dowody odnajdujemy w dokumentach tego okresu, spowodowana mogła być także niedoskonałością ortograficzną lub normami języka kancelaryjnego, w którym sporządzono akta. Na ewentualne pojawienie się tej lub innej litery mógł mieć wpływ również i sam pisarz lub kopista" [Tichoniuk 2000, 15].

Kanoniczne formy imion, pochodzące najczęściej z języka greckiego, hebrajskiego i łacińskiego, przekształcały się także w wyniku zmian morfologicznych. W rezultacie imiona chrześcijańskie upodobniały sie do form imion słowiańskich. Wspomniany proces polegał na wymianie lub odrzuceniu cząstek końcowych imion kanonicznych, a także na ich skróceniu do dwu- lub jednosylabowych segmentów imion (ucięcia nagłosowe, śródgłosowe, wygłosowe, mieszane) oraz na dodaniu odpowiednich formantów słowotwórczych. Niejednokrotnie oba te zabiegi były stosowane jednocześnie [Tichoniuk 2000, 14-60; Tichoniuk 2004, 157-162; Sajewicz 2012, 173-181].

\section{Transformacja imion chrześcijańskich XVI-wiecznych mieszkańców miasta Kleszczele na Podlasiu}

Imiona mieszkańców miasta Kleszczele w połowie XVI w. z rzadka pokrywały się z ich odpowiednikami kanonicznymi, por. np. Dawid - cerk. Давид, Konon-cerk. Конон, Nikita-cerk. Hикита, Nikon-cerk. Никон, Roman - cerk. Роман, Timon - cerk. Тимон. Czasem były tożsame z imionami używanymi przez Polaków: por. np. Andrzej, Jakub, Michał, Szymon, Szczęsny.

Formy imienne XVI-wiecznych mieszkańców Kleszczeli najczęściej w znaczny sposób różniły się od swoich odpowiedników cerkiewnych, por. Alus-cerk. Aleksandr, Antys-cerk. Aнфuм, Chacz-cerk. Харитон, Cham 
- cerk. Фома, Chanko - cerk. Фантин, Chrocz-cerk. Флор, Choman-cerk. Аммон, Daсz - cerk. Даниил, Frot-cerk. Флор, Нарип-cerk. Агафон, Helian - cerk. Илья, Hryсz - cerk. Григорий, Hurсz - cerk. Гурий, Jackocerk. Иакинф, Jarywon - cerk. Иларион, Jottuch - cerk. Eвтихий, Juchno - cerk. Евфимий, Kalisz-cerk. Каллистрат, Косz-cerk. Константин, Konach - cerk. Конон, Кисz-cerk. Акутий, Lasko - cerk. Илья, Luсzcerk. Лука, Mielech - cerk. Емилиан, Ochrym - cerk. Eфрем, Olichwier - cerk. Елевферий, Onасz - cerk. Ионафан, Pac-cerk. Иnатий, Pieczcerk. Петp, Pierchur-cerk. Порфирий, Sacz-cerk. Иcaaк, Siechen-cerk. Евсигний, Sieliwon - cerk. Сильван, Supron - cerk. Софроний, Wołos cerk. Власий, Zych-cerk. Исихий.

Adaptacja fonetyczna [por. Tichoniuk 2000, 15-25] imion cerkiewnych polegała m.in. na:

a) zastąpieniu dźwięków obcych rodzimymi:

- zamianę spółgłoski f na ch, np. cerk. Aнфuм - Anchim, cerk. Евфuмий - Juchno, cerk. Ефрем - Ochrym, cerk. Исихий - Zych, cerk. Софония - Sachniey, cerk. Трофим - Trochim, cerk. Фантин Chanko, cerk. Фома - Choma, Cham, Chamko;

- zamianę spółgłoski $f$ na chw, np. cerk. Елевферий - Olichwier, cerk. Парфений - Parchwien, cerk. Феодор - Chwedor, Chwiedko, Chwieduła, cerk. Феона-Chwien;

- zamianę spółgłoski $f$ na $p$, np. cerk. Агафон - Hироn, Hapun, cerk. Афанасий - Panas, Panasz, cerk. Евстафий-Ostap, cerk. Иосиф - Josip, cerk. Никифор - Niczypor, cerk. Софроний - Supron, cerk. Cтефан - Stepan;

- zamianę spółgłoski $f$ na $t$, cerk. Анфuм - Antys, cerk. Фарнакий Tarmocz; cerk. Фома - Tomasz, Tomko;

b) wymianie samogłoski $g$ na $h$, np. cerk. Агафон - Hapun, Hupon, cerk. Герасим - Harasim, cerk. Григорий - Hryc, Hrycko, Hrycz, Hryczko, Hryć, Hryn, Hryń, cerk. Гаврuил - Hauryło, Hawryło, Hacz, cerk. Галактион - Halka (m), cerk. Гордий - Hordiey, Hurodic, cerk. Герасим-Harasim, Haraczym, cerk. Гурий-Hurсz, Hигесz, cerk. Игнатий - Ihnat;

c) występowaniu pojedynczej głoski na miejscu obcej grupy samogłoskowej:

- $a a-a$, por. cerk. Исcaћ-Sacz;

- aа - o, por. cerk. Aвраaм - Awron;

- ео - e, por. cerk. Симеон - Siemien; cerk. Феодор - Chwiedor, Chwiedko, Chwiedzko, Chwieduła, por. cerk. Феона - Chwien;

- ео - o, por. cerk. Симеон-Siemon; 
- eо - u, por. cerk. Георгuй ( $\geq$ Jeorgius, Jeorius $\geq$ Jurgi, Jurg, Jurga, Jur) - Jurko;

- $i i-i$, por. cerk. Гавриил-Hawryło, cerk. Даниил-Daniło, cerk. Muxauл - Michat, Misko;

- io - e, por. cerk. Дионисий - Denis, Denisz;

- io - o, por. cerk. Иосиф - Josko;

- оа - a, por. cerk. Иоаким - Jakim, cerk. Иоанн - Ian, Jan, Janko, Janucz,

d) występowaniu spółgłosek epentetycznych, np. cerk. Иларион - Jarywon, cerk. Иоанн - Iwan, Jwan, cerk. Кион - Kiwon, cerk. (stare) Leon - Lewon, Lewoń, cerk. Леонтий - Lewontij, cerk. Лукиан - Eukijan, cerk. Родион - Radiwon;

e) pojawieniu się spółgłoski pojedynczej na miejscu spółgłoski zdwojonej (degeminacja):

- $l l$ - l, cerk. Kaллиник - Kalenik, Kalienik, Kalennik, Kalenyk, Kalinik, cerk. Kaллистраm - Kalis, Kalisz;

- $m m-m$, cerk. Аммон - Choman;

- $n n$ - n, cerk. Иоанн - Jan, Jwan, cerk. Сеннис - Sanisko, cerk. Ioannikij - Onikiey, Onikej;

- $p p$ - p, cerk. Филипn - Philip;

- ss - s, cerk. Coccuü - Susko;

- $t t-t$, cerk. Ammuŭ - Hacz $(c z \leq t)$;

- ww - w, cerk. Аввакум - Awoczko, Woczko, cerk. Савва-Sawka;

f) pojawieniu się spółgłoski zdwojonej na miejscu spółgłoski pojedynczej (geminacja), np. cerk. Афанасий - Pannas, cerk. Апрониан - Pronniecz, cerk. Каллиник - Kalinnik, cerk. Павел-Pawett;

g) uproszczeniu grup spółgłoskowych:

- $k s-s(\geq z)$, cerk. Максиан - Mazan;

- $m p-p(\geq b)$, cerk. Lampad - Lebied, Lebieda, Lebiecz;

- mps - ps, cerk. Сампсон - Samko

- nst - st, cerk. Kostyn, Kostian, Kostyan, Kostia, Kostiuk;

- wf-f $(\geq c h)$, cerk. Евфимий - Juchno;

- wf - $f(\geq$ chw), cerk. Елевферий - Olichwier;

- wks - ks $(\geq x)$, cerk. Авксентий - Xionko;

- wst - st, cerk. Eвcmaфuŭ - Ostap, Ostapko.

h) braku głosek na początku imienia (afereza):

- а: cerk. Аввакум - Wосzkо, cerk. Агафон - Hарип, Hupon, cerk. Азадан - Zdan, cerk. Акутий - Kисz, Kисzko, cerk. Аммон -

1 Forma Samko może także pochodzić od imienia cerk. Самуил. 
Monko, cerk. Апрониан - Pronniecz, cerk. Афанасий - Panas, Pannas, Panasz, cerk. Иоанникий - Onikiej;

- i: cerk. Иоанникий - Onikiey, Onikiej, Omikiej, cerk. Ионафан Onacz, Onaczko, cerk. Иnamuŭ - Pac, Pać, Pacz, Paczko, Paczuk, cerk. Иссак - Sacz, cerk. Исидор - Sidor, Sydor, cerk. Исuхий Zych, cerk. Иулиан - Utan, cerk. Иустиниан - Uscian, Ustian, Ustyan;

- j: cerk. Eвстафий (Jewstafij) - Ostap, Ostapko, cerk. Елевферий (Jelewfierij) - Olichwier, cerk. Eлисеü (Jelisiej) - Olisiej, cerk. Емилиан (Jemilian) - Amielian, Omilian, Omelian, Omielian, cerk. Ефрем (Jefriem) - Ofrem, Ochrym;

i) wymianie samogłosek nagłosowych imienia:

- а-о: cerk. Аверкий - Owierko, cerk. Алексий - Oleksiej, Oliexiey, Olexiey, Olexiej, Olixiej, Olixiey, Olexa, Oliexa, cerk. Анисий - Onisko, cerk. Анастасий - Onosko;

j) występowaniu głosek protetycznych przed $a$ i $e$ :

- $h$ : cerk. Аммон - Choman ( $\leq$ Homan), cerk. Ammuй - Hacz, cerk. Илья, pol. Eliasz, por. podl. Heliasz, Hielijasz [por. Tichoniuk 2000, 83] - Helian;

- w: cerk. Акила - Wakuła, cerk. Иеремия - Wieriemiey,

k) występowaniu głoski $j$ na miejscu samogłoski $i$ przed $a, o, u$, np. cerk. Иоаким - Jakim, cerk. Иоанн - Jwan, cerk. Иосиф - Josko;

l) występowanie pełnogłosu, np. cerk. Власuй - Wołos.

W analizowanych imionach chrześcijańskich znalazły także swoje odzwierciedlenie procesy zachodzące $\mathrm{w}$ przyjmującym systemie językowym [por. Tichoniuk 2000, 18-22]. Są to głównie różnorodne i rozbudowane wymiany głosek, które w znacznym stopniu różnicowały imiona kanoniczne i ich odpowiedniki występujące w XVI-wiecznych Kleszczelach.

$\mathrm{W}$ poddanym analizie materiale odnotowano $\mathrm{m}$. in następujące wymiany samogłoskowe:

- $a:$ : e cerk. Дамиан - Demian, Decz, cerk. Лампад - Lebied, Lebieda, Lebiecz;

- $a$ : о: cerk. Аввакум - Awoczko, Woczko, cerk. Авраам-Awron, cerk. Анастасий - Onosko, cerk. Патапий - Potap, cerk. Сильван-Sieliwon, cerk. Тарасий - Toraz², cerk. Татион - Тосz, cerk. Фарнакий - Tarmocz;

- $a$ : u: cer. Агафон - Hupon;

2 Mniej prawdopodobne jest wyprowadzanie badanej formy imiennej od imienia Tarazjusz. 
- е: a: cerk. Герасим - Harasim, cerk. Ермолай-Jarmosz, cerk. Сеннис - Sanko, Sanisko

- е: i: cerk. Алексий-Olixiej, cerk. Елевферий-Olichwier, cerk. Eфрем

- Ochrym; Olixiey, cerk. Лаврентий - Eawryn;

- е: o: cerk. Авксентий - Xionko;

- $i:$ : Зинон - Zan, Zań;

- $i$ : e: cerk. Евсигний - Siechen, cerk. Емилиан - Amielian, Omielian, Omelian, Mieliech, Mielien, cerk. Зиновий-Zien, Zienko, cerk. Kaллиник - Kalennik, Kalenik, Kalenyk, cerk. Muхеü-Miekiecz, Miekiecz, cerk. Сильван - Sieliwon, cerk. Симеон - Siemion;

- $i$ : o: cerk. Фотин - Chaton;

- $i$ : и: cerk. Aкила - Wakuta; cerk. Eвтихий - Jottuch, Jottuch; cerk. Kuприан - Kuprian, Kupryan;

- o: a: cerk. Родион - Radko, cerk. Софония-Sachmey, Sachniey, Sachmo, cerk. Фотин - Chaton;

- o : e: cerk. Порфирий - Pierchur, Pierchucz;

- o: и, por. cerk. Агафон - Нарип, cerk. Вукол - Wakuła, cerk. Косма - Kuzma, Kużma, cerk. Николай - Mikuła, cerk. Софроний - Suprun;

- $и:$ : Вукол - Wakuta;

- $u$ : o: cerk. Фрументий - Pronniecz;

Do licznych należą również wymiany spółgłosek. Szczególnie często występują alternacje spółgłosek typu:

- $t: c / c z / c ́$ : cerk. Аввакум - Awосzko, Woczko, cerk. Акутий, Акустий - Kuсz, Kuсzko, cerk. Акутион - Кисz, Кисzko, cerk. Артемий Arcys, Arcyś, cerk. Димитрий - Мic, Micz, Mycz, cerk. Дукитий Ducz, cerk. Иnamuŭ - Pac, Pać, Pacz, Paczko, Paczuk, cerk. Исaак - Sacz, cerk. Кутоний - Kисz, Kuсzko, cerk. Łuka - Łucz, Łuczko, cerk. Лукиан - Luc, Łucz, Luczko, cerk. Матвеŭ - Macko, Maćko, Macz, cerk. Нектарий - Niecz, cerk. Никифор - Niczypor, cerk. Петр - Piecz, cerk. Татион - Тосz;

Nieco rzadsze są wymiany spółgłosek typu:

- s : sz: Афанасий - Panasz, cerk. Дионисий - Denisz, cerk. Kaллиcmpam - Kalisz;

- ch: s: cerk. Muxauл - Misko ( $\leq$ Mis), cerk. Cmaxuü - Stas ${ }^{4}$;

- ch: sz: cerk. Пахомий-Paszka ( $\leq$ Pach), cerk. Tuмофеü $\geq$ Timoch Timosz, Tymosz;

- st : szcz: cerk. Cолосm - Soleszcz;

3 Formy Sanko, Sanisko mogą także pochodzić od imienia cerk. Aleksandr.

4 Forma Stas może również pochodzić od imienia Stanisław. 
Odnotowano również sporadyczne wymiany spółgłosek typu:

- $d: d z$ : cerk. Фeoдop - Chwiedzko;

- $l$ : l: cerk. Иулиан - Utan, cerk. Пелий - Pietko;

- $l$ : l: cerk. Власий - Wolos, cerk. Лонгuн - Lowin, cerk. Малахия Malko, Malka (m), Malos, cerk. Павел-Pa'lucz, cerk. Павел-Pawlis;

- $m: n$ : cerk. Авраам - Awron;

- $n$ : m: cerk. Андроник - Dromiecz, cerk. Николай - Mikula;

- $n:$ : cerk. Лонгин - Eochwin (interwersja);

- s: z: cerk. Косма - Kuzma, cerk. Tарасuй - Taraz;

- w: t: cerk. Eвтихий - Jottuch, Jottuch (interwersja);

- $w$ : ŭ: cerk. Гавриил - Ha'ryło, cerk. Павел-Pa'lucz. cerk. Савва$S a^{\prime} k a$;

Należy ponadto odnotować zjawisko interwersji, np. cerk. Лонгин - Łowhin, Łohwin, i metatezy, np. cerk. Fłor - Chrocz ${ }^{5}$, rozdzielenie grup spółgłoskowych samogłoską, np. cerk. Гордuŭ - Hurodic, kontrakcji, np. cerk. Азадан - Zdan, cerk. Иларион - Jarywon. Nie mniej ważną rolę pełniły również opozycje spółgłosek pod względem dźwięczności - bezdźwięczności i palatalności - niepalatalności.

$\mathrm{W}$ analizowanym materiale antroponimicznym odnotowano również cechy wynikające ze wzajemnego oddziaływania na siebie dwóch systemów imienniczych - prawosławnego i katolickiego [por. Tichoniuk 2000, 23-25]. Z języka polskiego zapożyczono następujące formy imion, które były używane przez mieszkańców miasta Kleszczele w połowie XVI w.: Andrzej, Bardko, Bartosz, Bartos, Bazyli, Grzegorz, Grześ, Jerzy, Jacko, Jan, Jurek, Staśko, Szczepan, Szymon, Tomko. Forma graficzna imion Andrzey, Ianko, Mikotay, Moysiey, Olexiey, Olexiej, Sebastyan, Woyciech, Woytek, Xionko została ukształtowana zgodnie z tradycją obowiązującą w języku polskim w okresie powstania badanego dokumentu lustracyjnego (XVI w.). Za hybrydalne należałoby natomiast uznać formy typu Wawres, Wawrys, które powstały od imion polskich Wawrzeniec, Wawrzyniec. Zwraca jednak uwage oddanie polskiego $r z$ pod wpływem ruskim przez $r$. Polszczyzna wywarła również wpływ na ukształtowanie się form imion Denis i Sydor, które tradycyjnie są oddawane w polszczyźnie z twardą wymową spółgłosek, por. także formy typu Wasyl, Tychon. Z kolei formy Anhicz, Mihat, Trohim, Trohym zaliczamy do hiperpoprawnych, ukształtowanych pod wpływem wschodniosłowiańskim. Natomiast formy hiperpoprawne Bochdan, Siechen uformowały sie pod wpływem języka polskiego.

5 Imię cerk. Fłor jest pochodzenia łacińskiego, por. wschsł. nazwisko Frolak (metateza). 
Poddane analizie imiona mieszkańców XVI-wiecznego miasta Kleszczele zawierają zazwyczaj więcej niż jedno przekształcenie fonetyczne. Formy imienne typu Olichwier - cerk. Eлевферий, Juchno - cerk. Евфимий, Jottuch-cerk. Eвтихий, Jottuch-cerk. Eвтихиŭ zawieraja nawet kilka takich przekształceń.

Proces adaptacji morfologicznej [Tichoniuk 2000, 26-40] imion chrześcijańskich polegał na upodobnieniu ich struktury do form rodzimych. W tym celu dokonywało się skracanie imion chrześcijańskich do jednej lub dwóch sylab i dodawanie do imion skróconych rodzimych formantów sufiksalnych.

Często ulegały wymianie końcowe cząstki imion, np. cerk. Алексий Alexiey, cerk. Андрей - Andrui, cerk. Гордий - Hordiey, cerk. Мокиŭ Mokiej. Końcowe cząstki imion kanonicznych mogły ulegać również odrzuceniu, np. cerk. Анисий - Anis, cerk. Василий - Wasil, cerk. Макарий - Makar, cerk. Парфений - Parchwien, cerk. Прокопий - Prokop, cerk. Tapacuü-Taras.

Formy imion powstawały:

- z początkowej części imienia cerkiewnego, np. cerk. Дукитий-Ducz, cerk. Зиновий - Zien, cerk. Зинон - Zan, Zań, cerk. Kаллистрат Kalis, Kalisz, cerk. Климент - Klim, Klym, cerk. Лаврентий - Lawren, Lawryn, cerk. Лукиан - Luc, Lucz, cerk. Mamфеü-Macz, cerk. Hектарий - Niecz, cerk. Петp - Piecz;

- z końcowej części imienia cerkiewnego, np. cerk. Исидоp - Sidor, cerk. Поликарп - Karp

- ze środkowej części imienia cerkiewnego, np. cerk. Aкymuü - Kucz, cerk. Димитрий - Мic, Мicz, cerk. Ипатий - Pac, Pać, Pacz, cerk. Исихий - Zych;

- z dwu różnych części imienia cerkiewnego, np. cerk. Константин Kot, Зинон - Zan [por. Tichoniuk 2000, 28]7.

Do skróconych form imion chrześcijańskich często dodawano sufiksy hipokorystyczne, które wnosiły do imion określone znaczenie emocjonalne. Najczęściej dodawano formant $\mathrm{z}$ podstawowym $k \mathrm{w}$ części sufiksalnej, por. np. Bard-ko, Hryc-ko, Jur-ko, Kucz-ko, Onis-ko, Pas-ko, Paszk-o, San-ko, Stecz-ko, Was-ko, Pacz-uk. Często również wykorzystywano sufiksy z podstawowym $c, c z, c$, por. Hry-c, Cha-cz, Hry-cz, Ste-cz, Hry-ć, Jarm-ocz, z podstawowym ch, por. np. Kon-ach, Piel-uch, z podstawowym sz, s, ś,

6 Imię Karp może także pochodzić od gr. karpos 'owoc'.

7 Forma imienna Zan mogła powstać w wyniku elizji środkowego elementu imienia cerkiewnego oraz alternacji o: а, Зинон $\geq$ Zan. Por. także formę Sien, która powstała z dwu różnych części imienia pochodzenia hebrajskiego Siemieon. 
por. np. Grze-s, Sta-s, Bart-os, Mart-ys, Mat-ys, Bart-osz, z podstawowym $n$, ń, por. np. Hry-n, Hry-ń. Pozostałe typy formantów sufiksalnych dodawano do skróconych form imiennych rzadziej. Odnotowano także nieliczne przypadki dołączania sufiksów do pełnych form imion chrześcijańskich.

Słusznie zauważył B. Tichoniuk, że materiał antroponimiczny zawarty „w dawnych aktach sporządzonych według wszystkich zasad panującego języka kancelaryjnego nie jest wolny od ówczesnej niedoskonałości ortograficznej. Struktury graficzne niektórych nazw mogą zawierać także zmiany wprowadzane (najczęściej nieświadomie) przez osobę sporządzającą dokument. Dlatego też różnice pomiędzy zmianami fonetycznymi a graficznymi są niekiedy trudno uchwytne" [Tichoniuk 2000, 25]. Uwaga ta dotyczy m.in. używanych w XVI w. w Kleszczelach form imiennych, które w wygłosie zawierają grafemy $c, c z$ i ć. Analiza materiału wykazała, że grafem $c z$ mógł być wówczas użyty na oznaczenie trzech różnych dźwięków - [c], [cz] i [ć], por. np. antroponimy Sac Burmistrz i Sacz Burmistrz odnoszace się do tego samego mieszkańca miasta Kleszczele [Tichoniuk 2000, 31].

Pomimo licznych niedoskonałości i ewidentnych pomyłek, rejestr pomiary włócznej starostwa kleszczelewskiego z 1560 r. stanowi doskonałe źródło wiedzy o imiennictwie osobowym mieszkańców tego miasta podlaskiego w połowie XVI w. i o początkach kształtowania się na tym terenie systemu nazwiskowego.

\section{Uwagi końcowe}

W rejestrach pomiarowych sporządzonych w 1560 r. w Kleszczelach przez S. Dziewiałtowskiego uwzględniono ponad 600 właścicieli placów i gruntów w mieście i w pięciu sąsiednich wsiach-przedmieściach. Nazwiska w tym czasie były jeszcze dość rzadkie, najczęściej więc w rejestrach podawano imię i przezwisko właściciela gruntów.

Rejestry pomiarowe z 1560 r. są doskonałym i najwcześniejszym źródłem wiedzy o antroponimii XVI-wiecznych mieszkańców Kleszczeli i okolicznych wsi, w szczególności o ich imionach i przezwiskach, a także o początkach kształtowania się miejscowego systemu nazwiskowego.

Celem niniejszego opracowania był opis męskich form imiennych używanych przez mieszkańców miasta Kleszczele i jego przedmieść w połowie XVI w. Były to w zdecydowanej większości ludowe odpowiedniki imion cerkiewnych, rzadziej katolickich. Formy te ukształtowały się w rezultacie przekształceń struktury imion kanonicznych mających na celu dopasowanie ich do systemu językowego miejscowych gwar ukraińskich. Kanoniczne formy 
imion, pochodzące najczęściej z języka greckiego, hebrajskiego i łacińskiego, najczęściej przekształcały się w wyniku daleko idących ucięć (nagłosowych, śródgłosowych, wygłosowych, mieszanych) i dodawania odpowiednich formantów słowotwórczych. Niejednokrotnie oba te zabiegi były stosowane jednocześnie.

\section{Literatura}

Atlas gwar wschodniostowiańskich Białostocczyzny, t. I, red. S. Glinka, A. Obrębska-Jabłońska J. Siatkowski, 1980, Wrocław.

Jabłonowski A., 1909a, Polska XVI wieku pod względem geograficzno-statystycznym, t. VI: Podlasie (województwo), cz. II, Warszawa (Źródła Dziejowe, t. XVII).

Jabłonowski A., 1909b, Polska XVI wieku pod względem geograficzno-statystycznym, t. VI: Podlasie (województwo), cz. III, Warszawa (Źródła Dziejowe, t. XVII).

Kamera Wojenna i Domen Prus Nowowschodnich w Białymstoku. Archiwum Pań stwowe w Białymstoku, sygn. 2674.

Miasto i gmina Kleszczele, http://www.kleszczele.pl/

R. E., 1934, Kleschtscheli, [in:] Encyclopaedia Judaica das Judentum in Geschichte und Gegenwart, Bd. 10, Berlin.

Roszczenko M., 2002a, Kleszczele, Bielsk Podlaski - Kleszczele.

Roszczenko M., 2002b, Aneks, [w:] Kleszczele. Kлiщелi. Bielsk Podlaski - Kleszczele.

Roszczenko M., 1979, por. Gwary okolic Kleszczel, Fonetyka, fleksja, Lublin (maszynopis rozprawy doktorskiej przygotowanej pod kierunkiem prof. dr hab. M. Łesiowa, Archiwum UMCS w Lublinie).

Sajewicz M., 2012, Jednozgłoskowe formy skróconych imion osobowych używanych na Podlasiu wschodnim w XVI-XVII wieku, ,Acta Albaruthenica” 12, red. M. Khau stovich, M. Timoszuk, Warszawa, s. 173-181.

Sajewicz M., 2014, Imiennictwo męskie miasta Kleszczele i okolic na Podlasiu w potowie XVI stulecia, „Studia Białorutenistyczne” 8, red. M. Korzeniowski, S. Kawalou, M. Sajewicz, Lublin.

Sankiewicz I., Miasto Kleszczele na Podlasiu, z przydaniem widomości o Jadźwingach, „Biblioteka Warszawska”, 1845, t. III,

$W$ województwie podlaskim w ziemi bielskiey lustracja starostwa kleszczelewskiego przez Dziewialtowskiego w roku tysiąc pięćset sześcdziesiatym czyniona z pomiara włoczna y placowa, [Żródło: Archiwum Państwowe w Białymstoku, Kamera Wojenna i Domen Prus Nowowschodnich w Białymstoku, sygn. 2674].

Tichoniuk B., 2004, Transformacja nazwisk wschodniostowiańskich w Polsce na przyktadzie niektórych struktur antroponimicznych z sufiksem -uk/-czuk, [w:] Ze studiów nad językami i literaturami wschodniostowiańskimi, red. B. Tichoniuk, W. Wilczyński, Zielona Góra. 
Zieleniewski J., 1991, Rejestr pomiary włócznej Kleszczel z 1560 roku, „Studia Podlaskie", t. III.

\author{
TRANSFORMATION IN THE STRUCTURE OF CANONICAL FIRST NAMES \\ IN THE TOWN OF KLESZCZELE IN PODLASIE IN THE MID-16TH CENTURY
}

\title{
S U M M A R Y
}

The land survey records made in 1560 in Kleszczele by S. Dziewiałtowski list over 600 owners of plots and land in the town and in the five neighboring villages-suburbs. At that time surnames were comparatively rare, therefore the records usually listed the first name and nicknames of the owner of land.

The land survey records of 1560 are the excellent ad earliest source of information about anthroponyms of the 16th-century inhabitants of Kleszczele and the surrounding villages, in particular about their first names and nicknames, and about the beginnings of the development of the local surname system.

The purpose of the present study is to describe male first-name forms used by the inhabitants of the town of Kleszczele and its suburbs in the mid-16th century. The overwhelming majority were the folk equivalents of Orthodox first names, less often of Catholic ones. These forms developed as a result of transformations in the structure of canonical first names, aiming to adjust them to the language system of the local Ukrainian dialects. The canonical forms of first names, most often originating from Greek, Hebrew and Latin, were usually transformed as a result of far-reaching truncations (initial, medial, and final) and additions of appropriate derivational morphemes. The two procedures were frequently used at the same time. Michał Sajewicz e-mail: msajewicz@gmail.com 